\title{
BREVES CONSIDERAÇÕES SOBRE A TERRITORIALIZAÇÃO DO PROGRAMA UMA TERRA E DUAS ÁGUAS NO ESTADO DO CEARÁ-BRASIL
}

\author{
Renato Cesar Aragão Mendes Junior ${ }^{1}$
}

\begin{abstract}
Resumo: O semiárido brasileiro vem assistindo, nas últimas décadas, a mudanças na forma como as políticas públicas têm encarado o problema da seca. Em vez de combatê-la, o discurso agora é o da convivência. Nesse sentido, o presente artigo tem como objetivo principal refletir sobre os elementos constitutivos do paradigma dominante - o combate à seca - e do paradigma emergente - a convivência com o semiárido. Toma-se por base para a análise a experiência do Programa Uma Terra e Duas Águas $(\mathrm{P} 1+2)$, uma política pública de convivência com o semiárido criada em 2007 pela Articulação do Semiárido (ASA) que tem o objetivo de promover segurança e soberania alimentar e possibilitar a geração de renda às famílias que são beneficiadas. A discussão dos conceitos apresentados ao longo do trabalho e dos dados apresentados contribui para entender a abrangência do referido programa no estado do Ceará.
\end{abstract}

Palavras-chave: Convivência com o Semiárido; Política Pública; Tecnologia social.

\section{BRIEF CONSIDERATIONS ON THE TERRITORIALIZATION OF THE PROGRAM UMA TERRA E DUAS ÁGUAS IN THE STATE OF CEARÁ - BRAZIL}

Abstract: The Brazilian semiarid region has watched changes in the way how public policies have faced the issue of drought in the last decades. Instead of fighting it, the current discourse is about coexistence. In this sense, the present article has as its main goal to reflect upon the elements that constitute the dominant paradigm, the struggle against drought, and the emerging paradigm, the coexistence with the semiarid region. The experience of the Program Uma Terra e Duas Águas $(P 1+2)$ was taken as a basis for the analysis. This program is a public policy of coexistence with the semiarid region created in 2007 by Articulação do Semiário (Asa), which has the goal of promoting safety and enabling the generation of income to the families benefited. The discussion of the concepts approached throughout the work and the data presented contribute to understand the comprehensiveness of this program in the state of Ceará.

Keywords: Coexistence with the Semiarid Region; Public Policy; Social Technology.

\footnotetext{
${ }^{1}$ Mestre em Geografia pela Universidade Estadual Vale do Acaraú (UVA). renatocesar41@ @otmail.com Estudos Geográficos, Rio Claro, 17(1): 279-291, jan./jun. 2019 (ISSN 1678-698X) http://www.periodicos.rc.biblioteca.unesp.br/index.php/estgeo
} 


\section{INTRODUÇÃO}

A segunda década do século XXI marca novamente a ocorrência de uma seca, a maior dos últimos 100 anos, de acordo com a Funceme (2017). Quando se atravessa esses períodos de seca grande, é recorrente a desestabilização da economia rural sertaneja, sendo retomado o debate sobre quais mecanismos e ações estruturantes e/ou assistencialistas podem ser adotados por governos e pela sociedade civil no intuito de minimizar os prejuízos econômicos e socioambientais ocasionados por esse fenômeno climático, especialmente para os habitantes difusos da/na zona rural semiárida.

Nesse sentido, muitas vezes mudam-se os agentes e atores que estão à frente da gestão das ações, mas a essência permanece inalterada. O discurso oficial dos governos estaduais do Nordeste, por vezes reprisado pelo Governo Federal, reforça a necessidade de maior aporte de investimentos financeiros em infraestruturas hídricas, tais como, perfuração de poços, adutoras, construção de açudes e barragens e a tão propalada transposição do Rio São Francisco. As ocorrências de secas como as mais recentes "continuam a revelar a essência da anacrônica e resistente estrutura econômico-social do semi-árido" (VIDAL, 2001, p. 213). Tais ações, insistentemente, comunicam abertamente que a resolução do problema perpassa estritamente a questão hídrica e que, portanto, a seca como elemento dominante deve ser combatida.

Contudo, paralelo ao período de seca atual (2012-2017), constata-se a existência de alguns elementos políticos e sociais que, em outros períodos, não se verificava. Dados da Confederação Nacional dos Municípios (CNM, 2017) mostram que a região semiárida do Brasil apresentou de 2012 a 2015 prejuízos da ordem de $\mathrm{R} \$ 104$ bilhões com a seca. Entretanto, não tem havido registro de saques e invasões nas cidades e, ao contrário do que se pode pressupor, reduziram-se substancialmente as correntes migratórias para o Centro-Sul do país ou a ocorrência de óbitos por desnutrição ou sede no interior dos sertões. Por outro lado, algumas mudanças no âmbito popular vêm acontecendo desde os anos 90, oriundas de uma força coletiva e do pensamento crítico que têm sido forjados no semiárido, apontando como possível a sua viabilidade econômica, cultural, política, social e ambiental, buscando a convivência com esse ambiente de clima quente e seco.

Com base nessa discussão, o artigo propõe refletir sobre uma política pública de convivência com o semiárido denominada Programa Uma Terra e Duas Águas $(P 1+2)$, implantado, em 2007, pela Articulação do Semiárido (ASA), que objetiva, por meio de um conjunto de tecnologias sociais hídricas, promover segurança e soberania alimentar, além de possibilitar a geração de renda para famílias rurais difusas do semiárido nordestino. Tentar-se-á conduzir esta exposição, analisando-se os elementos constitutivos do paradigma do combate à seca e o paradigma da convivência com o semiárido, além de trazer informações estatísticas e cartográficas no intuito de mostrar a territorialização do referido programa no estado do Ceará.

\section{O COMBATE À SECA E A CONVIVÊNCIA COM O SEMIÁRIDO}

A região semiárida do Brasil possui $969.589,4 \mathrm{~km}^{2}$, abrangendo um total de 1.333 municípios de oito estados do Nordeste, mais a parte setentrional de Minas

Estudos Geográficos, Rio Claro, 17(1): 279-291, jan./jun. $2019 \quad$ (ISSN 1678-698X) http://www.periodicos.rc.biblioteca.unesp.br/index.php/estgeo 
Gerais (BRASIL, 2005). Entre as outras áreas semiáridas do globo, é a de maior índice pluviométrico médio, girando em torno de $800 \mathrm{~mm}$ anuais. Mesmo sendo conhecida por ser uma região de ocorrência de chuvas irregulares no tempo e no espaço, o semiárido brasileiro registra historicamente um substancioso adensamento populacional, com estimativas do IBGE para o ano de 2014 de cerca de 23,8 milhões de habitantes, o que corresponde a $11,84 \%$ da população do país. Sobre esse adensamento populacional, Ab'saber (2003, p. 92-93) afirma que, no sertão, "o homem está presente um pouco por toda a parte, convivendo com o ambiente seco e tentando garantir a sobrevivência de famílias numerosas".

A seca é um elemento histórico e simbólico do Nordeste, promovedora de estereótipos regionais. De modo equivocado, atribui-se à própria seca o histórico de miséria e pobreza socioeconômica evidenciado na região. Partindo desse entendimento, este recorte regional desenvolveu, sobretudo ao longo do século $\mathrm{XX}$, um papel de ator coadjuvante no contexto da industrialização brasileira, sendo responsável basicamente "por fornecer mão-de-obra barata para quase todas as outras regiões detentoras de algum potencial de emprego" (AB'SABER, 1999, p. 26). Assim, tem-se que:

A formação do espaço geo-econômico do Semiárido foi organizada inicialmente com a pecuária extensiva e a policultura. Sobressaíram alguns produtos de maior expressão no mercado, como foi o caso do algodão, lembrando aqui, que sempre presente, uma estrutura fundiária pautada na concentração de terras que beneficia, sobretudo as classes dominantes e provoca a espoliação das massas trabalhadoras, fato que ao longo da história sertaneja várias ligas camponesas e movimentos sociais do campo se organizaram (CARVALHO, 2004, p. 6).

No século XIX, após a consolidação da ocupação humana na região por meio da pecuária e também do algodão, ocorre uma das maiores secas de que se tem registro, com relatos, inclusive, de mortes de centenas de milhares de nordestinos. O flagelo causado por esta seca escancara os problemas da região para todo o país, mormente espetacularizado pela literatura de cunho regionalista que ascendia ao cenário nacional à época, obrigando o governo imperial a iniciar a fase de estudos sobre o semiárido e, assim, formular políticas destinadas a solucionar tais problemas (SILVA, 2003).

Com isso, o século seguinte assiste a uma profusão de medidas elaboradas e aplicadas pelo Estado, como resposta às oligarquias políticas dos estados nordestinos, instalando-se um cenário em que "o aparato discursivo vigente desenha uma geografia das secas e da miséria, desenvolvendo como base de ações e políticas a lógica do combate à seca" (CARVALHO, 2004, p. 4). Nesse período, predomina uma visão simplista e reducionista dos problemas existentes, elegendo equivocadamente a questão hidráulica como foco das ações a serem desenvolvidas e implementadas pelo Estado, ou seja, "a visão parcial do semiárido, como a região das secas, conduziu à adoção de soluções fragmentadas, cujo núcleo gerador é o combate à seca e aos seus efeitos" (SILVA, 2003, p. 467).

As ações que caracterizam o paradigma do combate à seca podem ser definidas como:

Políticas que estavam e estão voltadas para grandes obras, normalmente destinadas a assistir aos mais ricos e que vinham

Estudos Geográficos, Rio Claro, 17(1): 279-291, jan./jun. 2019 (ISSN 1678-698X) http://www.periodicos.rc.biblioteca.unesp.br/index.php/estgeo 
Breves considerações sobre a territorialização...

unidas a projetos assistencialistas voltados para os mais pobres, como doações, esmolas, distribuição de víveres, carros-pipa e ações semelhantes. Essas políticas nunca tiveram, nem têm objetivo de resolver as questões e os problemas. As ações de combate à seca sempre aparecem como "atos de bondade", mas propositalmente são criadas e mantidas para garantir que o Semiárido e seu povo permaneçam sem vez e sem voz, dependentes (BAPTISTA; CAMPOS, 2013, p. 48).

A materialização das ações de combate à seca deu origem ao fenômeno da "indústria da seca", comportamento sociopolítico que muito se beneficiou do drama dos sertanejos, como mostra Silva (2003, p. 472) quando diz que, "desde as primeiras iniciativas governamentais, pesaram os interesses políticos das oligarquias sertanejas no Nordeste, transformando o combate à seca em um grande negócio". Um traço marcante da indústria da seca foi a construção de centenas de açudes e barragens no interior dos latifúndios para suprir a falta d'água e amenizar o drama social dos sertanejos, o que era pouco provável de acontecer, uma vez que o proprietário, alegando o direito de propriedade sobre a terra, lançava restrições e/ou mesmo impedia os moradores de se beneficiarem com tais obras, ampliando 0 quadro de sofrimento, desigualdade e pobreza regionais.

Os inúmeros programas criados no decorrer do século continuaram atuando na mesma linha de raciocínio, ou seja, de que o problema do Nordeste era a falta d'água e que, portanto, era necessário uma política hidráulica cujas ações atingissem diretamente o foco da causa. Esse modelo de intervenção estatal no semiárido para socorrer a sua população é entendido como uma tentativa de sobrepor o homem à natureza, com o auxílio da técnica e do progresso científico alcançado pela humanidade. A elaboração e aplicabilidade de políticas de desenvolvimento para as regiões secas do globo, e não somente para o semiárido brasileiro, perpassa um contexto de predação dos recursos naturais e de manutenção da condição de miséria e subserviência da maioria das populações que habitam a periferia do capitalismo mundial, em detrimento de uma minoria usurpadora da liberdade e dos direito sociais, assim:

Durante años, ha sido implantadas políticas gubernamentales para el desarrollo de estas regiones, orientadas casi que exclusivamente para "Combatir la seca y sus efectos y para agricultura irrigada de grandes proyectos". En común estas dos propuestas, combinan las siguientes características a) exploración económica, como elemento que define la ocupación y el uso del espacio, ejerciendo dominación local, b) visión fragmentada y tecnicista de la realidad local y c) aprovechamiento político de los elementos anteriores, en beneficio de las élites políticas y económicas que ejercen dominio local (BARBOSA, MACEDO, MEDEIROS, 2016, pp. 3-4).

Por conseguinte, depreende-se que a problemática nordestina, que corriqueiramente reacende o debate em torno de sua solução no interior das universidades e dos centros de pesquisa pelo país, está para além de se restringir ao viés hidráulico, necessitando mesmo que as políticas e os programas desenvolvidos lancem um olhar capaz de abarcar a diversidade social e ambiental existente no semiárido, bem como promover mudanças na estrutura fundiária regional, para que assim os governos possam elaborar e desenvolver propostas que se aproximem da realidade vivida pelos sertanejos e que ensejam 0

Estudos Geográficos, Rio Claro, 17(1): 279-291, jan./jun. 2019 (ISSN 1678-698X) http://www.periodicos.rc.biblioteca.unesp.br/index.php/estgeo 
desenvolvimento sustentável da região. Historicamente, tem se constatado que "as políticas públicas não se preocupam em olhar este lugar e escutar com atenção seu povo, apenas repetem há décadas uma postura de descomprometimento, justificada na maioria das vezes por uma suposta inviabilidade econômica e produtiva da região" (CHACON; BURSZTYN, 2005, p. 16).

Caminhando na busca de um desenvolvimento econômico e sustentável que atenda as necessidades das populações dessas áreas e que dialogue com as especificidades ambientais locais, emerge nos anos 80 uma concepção crítica que evidencia a impossibilidade de se combater as manifestações da natureza - nesse caso, a seca - e que, portanto, deve se adotar uma postura de convivência com os elementos naturais que fazem do semiárido uma região tão diversa.

A partir da redemocratização brasileira nos anos de 1980, emergem, em todo o território nacional, diversos movimentos sociais do campo e da cidade, detentores de um pensamento radical e crítico que se opõe às políticas neoliberais e que passam a se contrapor às injustiças sofridas pela população e aos graves problemas estruturais pelos quais passava o país naquele período. No semiárido, difundem-se experiências comunitárias ligadas ao cuidado com a natureza, a exemplo da preservação do ecossistema sertanejo e da vegetação de caatinga, objetivando libertar os povos do semiárido do eterno sofrimento com a seca, ensinando-os como proceder a um planejamento eficaz para o convívio com a natureza semiárida, como reforça Jalfim (2014, p. 5):

\begin{abstract}
A partir da década de 1980, iniciou-se uma convergência entre iniciativas de diferentes partes do Semiárido que tentavam romper com o paradigma do "combate à seca". Assim, gradativamente foi se constituindo uma rede de trocas de experiências e luta política na perspectiva da convivência com o Semiárido, as quais envolviam diretamente agricultoras e agricultores, associações rurais, movimentos sindical e social do campo, ONGs, Igrejas e setores das universidades e centros de pesquisa.
\end{abstract}

O esforço coletivo dos diferentes atores envolvidos torna-se cada vez mais robusto, ganhando espaço dentro dos locais de decisão e afirmando, segundo Furtado (1998, p. 8), que a problemática "é muito mais social que natural". A emergente concepção de que não se pode combater as manifestações da natureza, disseminada pelos atores que estão por trás do discurso da convivência com 0 semiárido, acompanha as preocupações das principais potências econômicas mundiais em relação aos problemas com o aquecimento global e à exaustão dos recursos naturais, qual seja, o movimento ambientalista que começa a ganhar espaço no cenário político internacional (LEFF, 2001).

No semiárido, as diversas experiências que vão sendo desenvolvidas no interior das pequenas propriedades rurais passam a ter o apoio e a assistência de Organizações Não Governamentais (ONGs), sindicatos de trabalhadores rurais, pastorais sociais e Comunidades Eclesiais de Base (CEBs), entre outros atores sociais que incorporam a figura do agente provedor de soluções e/ou de possibilidades que, paulatinamente, vão melhorando o cotidiano do sertanejo.

Estas organizações agem de forma autônoma, articulada e organizada no diálogo com a sociedade e os poderes públicos nos seus diferentes níveis. São expressões claras de um processo em que as populações historicamente oprimidas, excluídas dos

Estudos Geográficos, Rio Claro, 17(1): 279-291, jan./jun. 2019 (ISSN 1678-698X) http://www.periodicos.rc.biblioteca.unesp.br/index.php/estgeo 
Breves considerações sobre a territorialização...

mecanismos decisórios, começam a estabelecer novas correlações de forças políticas em torno de decisões de interesse público, das regras sociais e, sobretudo, da natureza e finalidade dos investimentos públicos (JALFIM, 2014, p. 12).

A distância histórica entre as intervenções estatais e os verdadeiros problemas que atingem a vida das populações rurais do semiárido é agora suprida em parte - pela atuação em rede dessas organizações em todo o semiárido e que vão promovendo uma consistente e importante articulação de conhecimentos práticos sobre a realidade socioeconômica e ambiental do semiárido.

É justamente essa metodologia empregada - somada a outras características próprias existentes nessa nova maneira de pensar sobre as questões que secularmente afligem os "Josés" e as "Marias" do sertão - que sustenta a existência de uma transição paradigmática em curso no semiárido. Assim, a noção de paradigma "compreende um conjunto de regras, suposições teóricas e técnicas de aplicação de leis que orientam as atividades dos envolvidos no processo de pesquisa da comunidade científica" (CONTI; PONTEL, 2013, p. 23).

Se outrora o arcabouço técnico-conceitual-operacional enxerga o ambiente hostil da caatinga como um obstáculo e que, portanto, precisa ser modificado e superado à custa de uma racionalização que nega as interações vitais entre natureza e sociedade, agora os preceitos fundamentais que legitimam a relação homem-natureza no semiárido são atravessados pela ótica da observação, convivência e adaptação, num movimento (in)consciente de transformação coletiva do pensamento. Desse modo, cabe ressaltar que:

A passagem de um paradigma para outro se configura como uma revolução científica que influi na mudança de concepções de mundo. Esse processo aponta para a superação de valores e de paradigmas estabelecidos para se chegar a uma concepção do real que seja capaz de responder às questões que emergem no processo (CONTI; PONTEL, 2013, p. 22-23).

O conflito paradigmático existente no semiárido coloca de um lado o pensamento hegemônico materializado na figura do Estado paternalista, historicamente consolidado à custa do sofrimento humano, do "voto de cabresto" e da subordinação do homem nordestino aos desmandos da classe política da região; e de outro, a chegada de não apenas um, mas vários sujeitos que atuam articulados com um só propósito, que é estimular a capacidade humana no semiárido de desenvolver processos produtivos resilientes e adaptados às agruras do clima quente e seco.

Desse modo, impera lançar aqui o que seria esse movimento paradigmático que, ao longo de quase 40 anos, baseia-se nas experiências tecnológicas produtivas de pequenos agricultores rurais, na observação dos elementos da natureza e na valorização do saber das populações tradicionais que conformam essa complexa geografia sertaneja, para afirmar a real possibilidade de um desenvolvimento sustentável da região. Para Silva (2010b, p. 78):

Pode-se definir a "convivência com o semiárido" como sendo uma perspectiva cultural orientadora da promoção do desenvolvimento sustentável, cuja finalidade é a melhoria das condições de vida e a promoção da cidadania, por meio de iniciativas socioeconômicas e

Estudos Geográficos, Rio Claro, 17(1): 279-291, jan./jun. 2019 (ISSN 1678-698X) http://www.periodicos.rc.biblioteca.unesp.br/index.php/estgeo 
Breves considerações sobre a territorialização...

tecnológicas apropriadas, compatíveis com a preservação e renovação dos recursos naturais.

O paradigma da convivência age e reflete sobre os limites $e$ as potencialidades do lugar, seja do solo, da água, do relevo, do clima, da vegetação, etc., desenvolvendo, a partir disso, uma série de tecnologias sociais de baixo custo e que podem ser facilmente replicáveis, chegando aonde mais precisam, no lar do sertanejo. A noção de convivência deve ser vista numa perspectiva ampla, levando em consideração diversos aspectos do cotidiano das populações do semiárido. Silva (2008, p. 226) ressalta algo importante sobre esse novo paradigma ao afirmar que:

Não se trata simplesmente de novas técnicas, de novas atividades e práticas produtivas e de ações socioculturais. A convivência é uma proposta cultural que visa contextualizar saberes e práticas (tecnológicas, econômicas e políticas) apropriadas à semiaridez, reconhecendo a heterogeneidade de suas manifestações subregionais, considerando também as compreensões imaginárias da população local sobre esse espaço, suas problemáticas e alternativas de solução que se foram construindo e desconstruindo ao longo da história de sua ocupação.

O Governo Federal passou, na década passada, a financiar diversos programas e projetos na linha da convivência, estipulando metas audaciosas no que diz respeito ao número de pessoas a serem beneficiadas. Um dos programas criados recentemente e que vem promovendo alterações significativas na qualidade de vida das famílias beneficiárias é o Programa Uma Terra e Duas Águas $(P 1+2)$ da ASA, que busca ampliar o acesso, bem como a disponibilidade de alimentos e geração de renda para as famílias que habitam nas áreas rurais do sertão. Analisar a atuação do $\mathrm{P} 1+2$ no Ceará é, entre outras possibilidades, compreender esse programa à luz da sua abrangência e territorialização no estado do Ceará.

\section{A TERRITORIALIZAÇÃO DO PROGRAMA UMA TERRA E DUAS ÁGUAS NO ESTADO DO CEARÁ}

O estado do Ceará possui, segundo estimativas do IBGE (2016), aproximadamente 8.963.663 de habitantes distribuídos numa área territorial de cerca de $148.887,632 \mathrm{~km}^{2}$, dos quais, $86 \%$ da superfície estão diretamente inseridos no contexto do clima semiárido.

Nos últimos cinco anos, o Ceará vem enfrentando aquela que já é considerada a maior seca dos últimos 100 anos (FUNCEME, 2017), contabilizando prejuízos financeiros em diversos setores da economia, comprometendo o Produto Interno Bruto (PIB) do estado (IPECE, 2016). No entanto, não se registra episódios de desordem social nas pequenas cidades em função do fenômeno climatérico atuante, como ocorria em casos de secas passadas. Essa mudança possui forte correlação com a chegada, na última década, de políticas sociais afirmativas dos governos Lula (2003-2010) e Dilma (2011-2016), afinadas com o discurso neodesenvolvimentista a partir dos anos de 1990.

As conquistas sociais alcançadas nos últimos quinze anos no país - que no semiárido especificamente provocaram um impacto imediato na qualidade de vida e no bem-estar social das famílias economicamente desfavoráveis - são frutos de políticas e programas sociais. No âmbito dessas conquistas, encontram-se os Estudos Geográficos, Rio Claro, 17(1): 279-291, jan./jun. 2019 (ISSN 1678-698X) http://www.periodicos.rc.biblioteca.unesp.br/index.php/estgeo 
programas de convivência com o semiárido, que vêm viabilizando o desenvolvimento e a adoção de práticas resilientes de coexistência com as influências do clima semiárido.

A ideia de conviver com o semiárido emerge como uma orientação cultural para a promoção do desenvolvimento sustentável, gestada nos princípios da gestão participativa, descentralizada e coletiva das decisões. Nessa acepção, a convivência com o semiárido caminha com base na confluência de ideias e experiências de diversos atores espalhados pelos estados que fazem parte do polígono das secas, possuindo como núcleo central a Articulação do Semiárido (ASA), estabelecida como agrupamento em rede de mais de três mil organizações da sociedade civil de distintas naturezas - sindicatos rurais, associações de agricultores e agricultoras, cooperativas, ONGs, Organizações da Sociedade Civil de Interesse Público (OSCIPs), entre outras.

Entre as inúmeras ações desenvolvidas pela ASA no semiárido, destaca-se o Programa Uma Terra e Duas Águas $(P 1+2)$, que objetiva desenvolver e ampliar a cultura do estoque de água para as famílias da zona rural, visando atender as demandas por água exigidas em pequenos plantios e criações animais. Para ser contemplada, a família deve atender a critérios preestabelecidos pela ASA: possuir renda per capta de até meio salário-mínimo; estar inscrita no Cadastro Único para Programas Sociais (CadÚnico); ter Número de Identificação Social (NIS); possuir cisterna de água para consumo humano; ser beneficiada no caso de extrema pobreza; ser uma família chefiada por mulher, com crianças de 0 a 6 anos; manter as crianças frequentando a escola; e manter membros da família com 65 anos ou mais ou com deficiência física e/ou mental atendidas em caráter de prioridade (ASA, 2016).

Em 2007, a ASA desenvolve, em caráter experimental, o P1+2, beneficiando cerca de 818 famílias de 60 municípios do semiárido com as seguintes tecnologias sociais: cisterna-calçadão, barragem subterrânea, barreiro trincheira e tanque de pedra. O coordenador do Fórum Cearense pela Vida no Semiárido (FCVSA) destaca: "Em 2007, a gente teve uma primeira experiência. $E$ foi uma experiência de fato, experimental mesmo, um conjunto muito pequeno de famílias que foram atendidas e as primeiras construções". O financiamento ficou sob a responsabilidade da Fundação Banco do Brasil e da Petrobras, com apoio da Rede de Tecnologia Social (RTS). No Ceará, a Caritas Ceará e o Centro de Pesquisa e Assessoria (ESPLAR) foram organizações pioneiras na execução do $\mathrm{P} 1+2$, beneficiando algo em torno de 85 famílias.

Já em 2008, a ASA desenvolve a fase piloto do P1+2, beneficiando algo em torno de 3.414 famílias agricultoras, das quais, 410 no Ceará. Desta vez, as ações tiveram o apoio do Ministério do Desenvolvimento Social e Combate à Fome (MDS), da Companhia de Desenvolvimento do Vale do São Francisco e do Parnaíba (CODEVASF) e do Ministério do Desenvolvimento Agrário (MDA). Foram abrangidos 100 municípios do semiárido, sendo construídas cerca de 1.542 tecnologias, sendo 1.173 cisternas-calçadão, 161 barragens subterrâneas e 208 tanques de pedra. Desse total, 350 tecnologias foram construídas em municípios do território cearense.

O P1+2 trabalha atualmente com sete tecnologias sociais hídricas: cisterna calçadão (52.000 mil/l), cisterna enxurrada, barragem subterrânea, tanque de pedra, bomba d'água popular, barreiro trincheira e barraginha. Cada tecnologia a ser implementada deve obedecer às condições de relevo, hidrografia, geologia, solos, entre outras variáveis, uma vez que cada tecnologia é constituída por uma dinâmica própria, embora o objetivo final seja o mesmo. Ao ter acesso ao programa, a família

Estudos Geográficos, Rio Claro, 17(1): 279-291, jan./jun. 2019 (ISSN 1678-698X) http://www.periodicos.rc.biblioteca.unesp.br/index.php/estgeo 
passar por capacitações que visam prepará-las para o manuseio correto da tecnologia. $\mathrm{O}$ desenvolvimento do $\mathrm{P} 1+2$ no estado do Ceará atualmente é acompanhado pelo Fórum Cearense pela Vida no Semiárido (FCVSA), uma rede permanente de pastorais sociais, sindicatos rurais, associação de moradores e ONGs, que atuam em escala estadual por meio de nove microrregiões: Fortaleza, Sobral, Tianguá, Crateús, Iguatu, Sertão Central, Cariri, Limoeiro e Itapipoca. O FCVSA constitui, no estado, uma representação da ASA Brasil, que busca promover a reflexão e o debate acerca da acessibilidade de políticas públicas alternativas para o desenvolvimento sustentável por parte da população dessa área (FCVSA, 2017).

Em todo o semiárido cearense, as milhares de tecnologias sociais hídricas implantadas estão possibilitando aos agricultores atravessar com menos sofrimento os últimos sete anos de seca. Dados ${ }^{2}$ extraídos da Articulação do Semiárido Brasileiro (ASA) mostram que desde 2007 já foram construídas 253 barragens subterrâneas, 1.470 barreiros trincheira, 7.608 cisternas calçadão, 433 barraginhas, 77 bombas d'água popular e 4.787 cisternas enxurrada. Estes números refletem a espacialização das tecnologias do $\mathrm{P} 1+2$ no estado do Ceará, assim localizadas (figura 1):

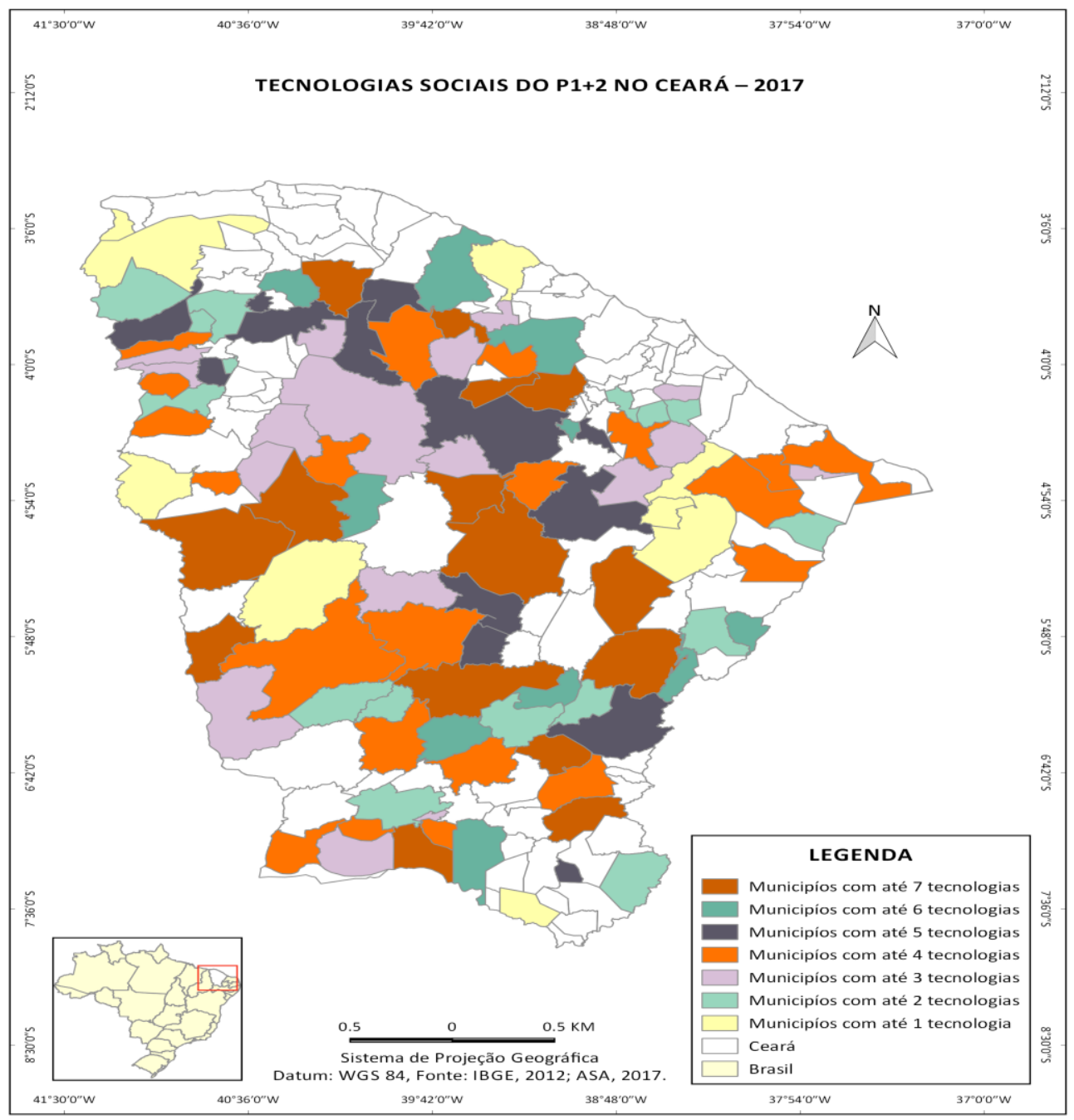

Figura 1 - Tecnologias sociais do P1+2 no Ceará em 2017

Fonte: Adaptado do IBGE, 2017.

\footnotetext{
${ }^{2}$ Dados extraídos do site: 〈http://www.asabrasil.org.br/mapatecnologias/\#>. Acesso em: 09. Out. 2017.

Estudos Geográficos, Rio Claro, 17(1): 279-291, jan./jun. 2019 (ISSN 1678-698X) http://www.periodicos.rc.biblioteca.unesp.br/index.php/estgeo
} 
Dos 184 municípios cearenses, somente 15 são beneficiados com sete tecnologias; 10 municípios com seis tecnologias; 13 municípios com cinco tipos de tecnologias; sendo que os municípios com quatro, três e duas tecnologias concentram a maior parte, perfazendo juntos um total de 53 tecnologias. Apenas 8 municípios detêm 1 tipo de tecnologia. Há de se atentar para o total de 87 municípios que não possuem tecnologias do $P 1+2$, o que representa quase $50 \%$ de todo o território cearense, cuja área semiárida no estado do Ceará é representada por $92 \%$ do território. Por outro lado, esses municípios em sua maioria se concentram nas regiões que apresentam os maiores índices de chuvas: a região do litoral e a maior parte da região sul do Ceará. Tal disposição heterogênea das tecnologias ao longo do espaço cearense pode ser explicada a partir a fala do representante do Fórum Cearense pela Vida no Semiárido:

\begin{abstract}
Essa demanda, ela é feita a partir dos próprios critérios que a ASA tem, né. Por exemplo, municípios com maior número de habitantes na região semiárida, municípios com maior índice de insegurança hídrica, né. Então, a partir desses critérios, a ASA como um todo, as organizações que compõe a ASA, é que elas indicam prioritariamente quais são os municípios e quais são as quantidades. É a organização politica da ASA que faz isso, tá certo? Por exemplo, fez um convênio com o MDS que no estado do Ceará vai vir uma meta de 10 mil cisternas de primeira água, tá, então a ASA estadual, a partir de sua articulação política, ela faz um diálogo de acordo com os municípios. Aqueles que têm maior necessidade, né, tem uma demanda maior, tem uma maior insegurança hídrica, e aí define isso, passa pra AP1MC, e a AP1MC vai legalmente elaborar o edital de seleção pública, então deixa isso tudo organizado (Entrevistado em 31 de março de 2017).
\end{abstract}

É no contexto da organização e articulação das populações que convivem e sofrem com a falta de água para beber e produzir que o Estado brasileiro, na última década, direcionou atenção especial aos programas sociais de convivência com o semiárido, desenvolvendo políticas públicas efetivas no tocante ao acesso à renda, à água e ao alimento, como mecanismos de redução da pobreza extrema, especialmente no semiárido brasileiro. No entanto, o Estado ainda é um forte agente das políticas de combate à seca no Nordeste, assim como também algumas ONGs envolvidas nesse processo de luta e mobilização por mais conquistas sociais, ou seja, "o Estado está sempre organizando o território nacional por intermédio de novos recortes, de novas implantações e de novas ligações" (RAFFESTIN, 1993, p. 152).

O semiárido cearense é historicamente marcado pela presença de uma territorialidade de caráter excludente e conservadora, consequência da concentração do poder pela elite política formada pelos coronéis da seca, simbolizando, portanto, a consolidação máxima do paradigma do combate à seca. Por outro lado, o acesso às tecnologias do $\mathrm{P} 1+2$ por parte das famílias representa bem mais que uma perspectiva de melhora na qualidade de vida, significa a criação de uma nova territorialidade, marcada, sobretudo, pelo viés democrático, sustentável e dialógico. Em outras palavras, "o que muda na construção dessa nova territorialidade é o enfraquecimento das elites oligárquicas e o surgimento de novos e diferentes atores, fomentando uma mudança de paradigma de desenvolvimento" (CARVALHO, 2004, p. 09).

Estudos Geográficos, Rio Claro, 17(1): 279-291, jan./jun. $2019 \quad$ (ISSN 1678-698X) http://www.periodicos.rc.biblioteca.unesp.br/index.php/estgeo 
Das rupturas do "combate à seca" aos avanços da "convivência com o semiárido", entende-se que:

Esse movimento promove ainda que de forma pontual, uma reorganização sócio-espacial do Semi-árido. E nesse novo contexto, um campo de força é estabelecido entre os "atores sociais", em suas relações de poder com o espaço, possibilitando a re-elaboração de novo recorte territorial, novas formas de inserir esse território às outras escalas espaciais e de demandar políticas públicas, já denominadas de apropriadas, às novas formas de produzir, ver e viver o Semi-árido Brasileiro. (CARVALHO, 2004, p. 08).

Por serem de baixo custo e facilmente replicáveis, as tecnologias sociais hídricas do $\mathrm{P} 1+2$ possuem um caráter descentralizador, conseguindo alcançar as famílias que se encontram difusas no semiárido cearense.

\section{CONSIDERAÇÕES FINAIS}

A territorialização do $\mathrm{P} 1+2$ no semiárido cearense nos últimos dez anos simboliza a forte atuação do terceiro setor no estado, acompanhada de parcerias institucionais realizadas junto a importantes ministérios do Governo Federal, que atua como principal agente financiador do programa.

Os resultados podem ser vistos, por exemplo, no momento atual de seca (2012-2017), em que as famílias estão conseguindo produzir - em pequena escala alimentos como coentro, tomate, cebola, abobrinha, entre outras variedades que incrementam o cardápio alimentar dos integrantes da casa. Além disso, o excedente é comercializado nas feiras ou mesmo na própria comunidade onde residem, gerando, assim, uma renda extra.

Programas como o $\mathrm{P} 1+2$ da ASA ainda carecem de ajustes quanto a alguns aspectos de sua operacionalização. Contudo, tem demonstrado ser uma saída viável para os problemas enfrentados pelos sertanejos do semiárido cearense, garantindo dignidade e qualidade de vida numa região marcada pela pobreza socioeconômica e fragilidade ambiental de seu ecossistema.

\section{REFERÊNCIAS}

AB'SÁBER, Aziz Nacib. Sertões e sertanejos: uma geografia humana sofrida. Estudos Avançados. Vol. 13, número 36. São Paulo. Mai/Ago. 1999. Disponível em: <http://dx.doi.org/10.1590/S0103-40141999000200002>. Acesso em: 05 set. 2016.

Os domínios da natureza no Brasil. São Paulo: Ateliê, 2003.

ANDRADE, Francisco Ari de. O sertão, as fazendas de gado e a ocupação espacial da capitania do Ceará. In: VASCONCELOS JÚNIOR, Raimundo Elmo de Paula et al. Hierópolis: o sagrado, o profano e o urbano. Fortaleza: Edições UFC, 2013.

ARTICULAÇÃO DO SEMIÁRIDO - ASA. Carta de Princípios. 2000. Disponível em: <http://www.asabrasil.org.br/>. Acesso em 12 mar. 2016.

Estudos Geográficos, Rio Claro, 17(1): 279-291, jan./jun. $2019 \quad$ (ISSN 1678-698X) http://www.periodicos.rc.biblioteca.unesp.br/index.php/estgeo 
Programa Uma Terra e Duas Águas (P1+2). 2009. Disponível em: <http://www.asabrasil.org.br/>. Acesso em 22 mar. 2016

BAPTISTA, Naidison de Quintella; CAMPOS, Carlos Humberto. Caracterização do Semiárido Brasileiro. In: CONTI, Irio Luiz; SCHROEDER, Edni Oscar. (Org.). Convivência com o Semiárido Brasileiro: autonomia e protagonismo social. Editora: IABS, Brasília-DF, Brasil, 2013.

BARBOSA, Humberto; MACEDO, Leandro; MEDEIROS, Salomão. La vulnerabilidad a la sequia y degradación de la región del semiárido del nordeste de Brasil: un enfoque en los aspectos biofisicos, económicos y sociales. Editorial Académica Española, 2016.

BRASIL. Nova delimitação do semi-arido brasileiro. Ministério da Integração Nacional, 2005. Disponível em: <www.mi.gov.br>. Acesso em: 16 fev. 2017.

Sistema de acompanhamento de reservatórios. Agência Nacional de Águas - ANA. Disponível em: <http://sar.ana.gov.br/Nordeste>. Acesso em: 11 mar. 2017b.

. Previsão climática sazonal. Ministério da Ciência, Tecnologia, Inovações e Comunicações - MCTIC. Disponível em: <http://www.cemaden.gov.br/wpcontent/uploads/2017/01/GTPCS Nota30 20012017.pdf>. Acesso em: 02 mar. 2017.

. Estados@ 2015. Site do Instituto Brasileiro de Geografia e Estatística IBGE. 2016. Disponível em: <http://www.ibge.gov.br/cidadesat/default.php>. Acesso em 07 mar. 2017.

. Estimativa da população por estados. Instituto Brasileiro de Geografia e Estatística - $\quad$ IBGE. 2015.2 Disponível em: <http://www.ibge.gov.br/estadosat/perfil.php?sigla=ce>. Acesso em: 07 mar. 2017.

CEARÁ. PIB Trimestral do Ceará: 3o Trimestre. Instituto de pesquisa e Estratégia Econômica do Ceará - IPECE. 2016, Contas Regionais, IPECE - Fortaleza, dezembro de 2016.2 Disponível em: $<$ http://www.ipece.ce.gov.br/estudos economicos/pib/apresentacao pib 3o trim201 6.pdf>. Acesso em: 10 mar. 2017.

CARVALHO, Luzineide Dourado. A emergência da lógica da "convivência com o semiárido" e a construção de uma nova territorialidade. In: RESAB, Secretaria Executiva. Educação para a convivência com o semi-árido: Reflexões teóricopráticas. 1르. Ed. Juazeiro: Secretaria Executiva da RESAB, 2004.

CHACON, Suely Salgueiro; BURSZTYN, Marcel. Análise das políticas públicas para o sertão semi-árido: promoção do desenvolvimento sustentável ou fortalecimento da pobreza?. $2005 . \quad$ Disponível em: <http://www.ecoeco.org.br/conteudo/publicacoes/encontros/vi_en/artigos/mesa5/anal ise_das_politicas_publicas.pdf>. Acesso em: 24 out. 2016.

Estudos Geográficos, Rio Claro, 17(1): 279-291, jan./jun. $2019 \quad$ (ISSN 1678-698X) http://www.periodicos.rc.biblioteca.unesp.br/index.php/estgeo 
FÓRUM CEARENSE PELA VIDA NO SEMIÁRIDO - FCVSA. Quem somos. Site do Fórum Cearense Pela Vida no Semiárido. 2017. Disponível em: <http://asaceara.blogspot.com.br/p/quem-somos.html>. Acesso em: 11 mar. 2017.

FUNDAÇÃO CEARENSE DE METEOROLOGIA - FUNCEME. Funceme prevê maior probabilidade de chuvas em torno da média. Site da Funceme. Disponível em: Disponível em: <http://www.funceme.br/index.php/comunicacao/noticias/774funceme-prev\%C3\%AA-maior-probabilidade-de-chuvas-em-torno-dam\%C3\%A9dia>. Acesso em: 10 fev. 2017.

FURTADO, Celso. Seca e Poder. São Paulo: Editora Fundação Perseu Abramo, 1998.

MALVEZZI, Roberto. Semiárido, uma visão holística. Brasília: Confea, 2007.

RAFFESTIN, Claude. Por uma geografia do poder. Tradução: Maria Cecília França. São Paulo: Ática, 1993.

SILVA, Roberto Marinho Alves Da. Entre dois paradigmas: combate à seca e convivência com o semiárido. In: Sociedade e Estado, v. 18, n. 1/2, p. 361-385, jan./dez. 2003. Disponível em: <http://www.scielo.br/pdf/se/v18n1-2/v18n1a16.pdf.>. Acessado em: 15. abr. 2016.

SOUZA, Marcos Jose Nogueira de. SANTOS. J.O. Bases naturais e esboço do zoneamento geoambiental do estado do Ceará. In: Souza, M.J.N. Moraes J. O. de e Lima, Luiz Cruz. Compartimentação territorial e gestão regional do Ceará, Parte I. Fortaleza Editora FUNECE. 2000 13-98.

VIDAL, Francisco Carlos Baqueiro. A problemática do semi-árido nordestino à luz de Celso Furtado: permanência da pobreza estrutural. Pobreza e desigualdade sociais. 2001. 197-217. Disponível em: <http://www.centrocelsofurtado.org.br/arquivos/image/201108311532340.F_VIDAL3. pdf. >. Acesso em: 16. ago. de 2016. 